\title{
Development Stage Exploration of Sports Television Broadcasting in
}

\section{China}

\author{
Kang Tan \\ Chengdu Sports Institute, Chengdu, China \\ Email:373024528@qq.com
}

\section{Keywords:Development Stage Exploration;Sports Television Broadcasting;China}

Abstract: Through dividing and analyzing the historical development of Chinese sports television stage, this paper summarizes the rules of development, in order to promote the better development of China's sports TV broadcasting.

\section{Introduction}

The development of China's sports TV broadcasting is accompanied by the prosperity of China's sports industry and the great progress of China's television industry. More than half a century, Chinese sports TV broadcasting has changed a lot both in quantity and quality. Part of China Central Television (CCTV) sports broadcast level has reached the international level. Due to special TV broadcasting system, China Central Television (CCTV) is typical of the highest level of Chinese sports television broadcasting.Thus when studying Chinese sports TV stage of development, we must take the development of CCTV sports television broadcasting as the main line, and comb the development of local TV sports broadcasting as a supplement.

\section{Results}

Throughout the development of China's sports television broadcasting, it can be divided into the following five stages.

Bud stage (1958-1958)

On May 1, 1958, Beijing television station (the predecessor of CCTV) emerged and began experimenting with the radio. After 4 months pilot, the official broadcasting started on September 2[1]. In the early days of TV shows, there used to be only one form, including the sports news, which become the seeds of Chinese sports TV. On June 19, 1958, Beijing television station (CCTV) broadcast the army men and women's basketball team and Beijing men's and women's basketball team performance, this is China's first sports TV broadcast. In addition, China central television (CCTV) successively broadcast the opening ceremony,football, basketball, volleyball and some other important match live during the first session of the national games in 1959. In April 1961, the 26th world table tennis championships held in Beijing, China central television broadcast 14 games within 10 days, which is 35 hours in total. The set-up of TV station from 1958 to the period before the "Cultural Revolution",television participated in the events' broadcasting mainly including "the first session of the national games" held in Beijing in 1959 and the "26th world table tennis championships"held in Beijing in 1961, as well as some domestic and international invitational tournaments"[2]. In the early development of Chinese sports TV, due to the restrictions on the material conditions and technical level, the Chinese sports broadcasting time section and hours were not regular, presented in a once in a while state. However, sports television 
broadcasting, which can be called the most program form on TV sports report, after all, emerged and came in front of the Chinese audience during this period.

Tortuous development stage (1966-1977)

During the "Great Cultural Revolution", China's development of sports TV appeared a stagnant or even serious backward, the vast majority of sports TV programs were banned,such as CCTV's "sports fans" and "sports", as well as TV sports programs of local stations all over the country. This situation has been improved until after 1972 such as the renewal of CCTV's "sports program" broadcasting.

China's TV sports industry in this period is struck with the political turmoil overall, but it also made certain progress on some TV transmission and production technology. For example, the initial events broadcasting of CCTV was always in conjunction with the central people's broadcasting station, shared the same call-sign and commentator. This kind of situation lasted for a long time[3]. Until the early 70s, China Central Television actually began live sporting events broadcasting independently. In October 1973, China Central Television (CCTV) cooperated with Hubei television station, achieved the first successful use of microwave trunk lines and delivered video and audio signals from Hubei to Beijing for the live broadcast in the country [4]. There wasn't a specialized sports channel in this period before reform and opening up in China, even almost no television station equipped with sports system and just a few of sports events television broadcasting . For example, "until 1974, Shanxi TV station live broadcast" the national youth table tennis championships" for the first time with heavy tube camera device"[5]. However, it is obvious that these sporadic sports on TV has already accumulated strength secretly for the rapid development of sports television broadcasting in China after the reform and opening up. Recovery stage (1978 1991)

In the early 1980s, China has begun to reform and opening up, all walks of life has changed dramatically. Chinese sports industry ushered the first climax of development. First of all, the number of Social possessions of television in China has reached of 30 million and being increased year by year. Then followed by after the reform and opening up, national rejuvenation requires emotional release, sports exactly play the function of such a "social relief". At this time, there is a chance, as well psychological needs, for Chinese to appreciate the performance of Chinese athletes in World Series and high-level competitions through sports television broadcasting.

After 1978, China Central Television (CCTV) began to broadcast events live on a large scale. On June 25, 26, 1978 and July 2, during the 11th World Cup semi-finals and final sheld in the Argentine capital, Buenos Aires, China Central Television (CCTV) sent TV image and sound signals back to China from abroad through international communication satellite and voice broadcast. This is the first sports live transmission in China's sports television history . In December 1978, the 8th Asian Games held in Bangkok, Thailand. CCTV sports journalists for the first time in the game through the communication satellite to domestic live sporting events.

In fact, in 1981, a series of big events happened in the history of Chinese sports, which were hard to forget until now. The Chinese table tennis team won seven titles in the world table tennis championships, and women's volleyball team won the world championship for the first time. The moving scene was precisely broadcast live through CCTV to Chinese people, it made the Chinese in the full understanding of the competitive sports as well as the live sports events at the same time, also. Additionally, it fully inspired Chinese patriotism and launched a strong sports boom all over the country. In November 1981, the women's volleyball World Cup, China Central Television (CCTV) made full coverage of the Chinese women's volleyball team won the 
first world championship game. During this period, in addition to CCTV, local TV sports broadcast have also gotten fast development. Within 14 days of the fifth national games in 1983, Shanghai television station broadcast 28 games on live.

The Olympic Games broadcast that China begin to participate in is the first one since China has returned to the Olympic family, the 23rd Los Angeles Olympic Games, this is the beginning of China's large-scale used in sports on TV international public signal. CCTVsuccessfully broadcast many wonderful competitions including the opening ceremony, closing ceremony, gymnastics, diving, weightlifting, fencing, handball, basketball, volleyball, judo and so on, More than 70 hours of programs were broadcast in total.

The 11th Asian Games held in Beijing in 1990 became a good opportunity for the development of the Chinese sports TV broadcasting. Beijing Asian Games also became a peak of the development of Chinese sports broadcasting naturally. In fact, China Central Television (CCTV) undertook the opening and closing ceremonies, athletics, football and other broadcast tasks of the project, while most of other projects were all assumed by another 17 local TV stations and Beijing broadcasting institute. This television coverage of the Asian Games is the first time that China broadcast intercontinental comprehensive sports events with the signal made by itself. It not only benefited China's sports broadcasting teams in talents training and experience accumulation, but also prepared good technology for the comprehensive prosperity of China's sports television broadcasting in the middle of 1990s.

\section{Comprehensive prosperity stage (1992-2004)}

Since 1992 after Deng Xiaoping's south China tour, the guidelines for China's reform and opening up became more clear, changes began to take place in various aspects such associal politics, economy, culture and so on. China's sports on TV has gradually stepped into prosperity. On December 12, 1993, the first cable TV sports channel, the Shanghai Television Station sports channel launched in Shanghai, now provide rich and colorful sports programs on TV to 2.2 million users in Shanghai, nearly 8 million audience in cities and towns in broadcasting capacity of 17 hours per day. On August 28, 1994, Guangdong Cable Television sports channel debuted and broadcast 14 hours a day on average. So far, China's sports TV also developed from previous scattered free state to professional sports channel which has quite influence and scale. The establishment of specialized channels offered rich broadcast time and enough exhibition space to sports broadcasting and formed the sports TV boom throughout the country.

Then, the China's Football League (First Division Group A League) launched in 1994provides rich sports events resources for CCTV and local TV broadcasting. It can be said that Division A League has caused great concern of the people exactly due to the television broadcasting on a large scale and became China's first league. These broadcasts, of course, also trained a large number of sports broadcasting technology backbone such as director, camera operator, and the video and audio staff for the local stations. Some of these people are still active in China's sports television broadcasting.

The premiere of CCTV Sports Channel in 1995 further provided round-the-clock coverage of space for sports broadcasting, thus sports fans could enjoy more sports TV programs. At the same time, it also got ready with a lot of channel resources for CCTV's numerous sports broadcasting. Since then, CCTV Sports Channel made full use of the times and style-characteristic signal coverage advantages of specialized channel, thus made itself become "the First Sports Channel" in China. During this period, in addition to the Division A League, CCTV and local TV actively developed many new sports broadcast program resources such as the Football 
World Cup, European Football Five League, NBA and CBA, volleyball league and so on, thus, Chinese sports TV channels became more prosperous.

Entering the new century, China's sports television still followed a healthy development track. Sydney 2000 Olympic Games, which became "China sports coverage to mature" one. China sent a team with 108 people, which achieved synchronization. China joined the WTO in 2001, thus further enhanced its internationalization degree, just at this time, a wave of collectivization and specialization boomed in radio and television industry. Combined with the successful Olympic bid in July in this year, the success in impacting World Cup in October, combination of various conditions and factors, China's sports TV had a new development, which represented as further improvement in sports events broadcasting skill and the increase in the number of local professional sport channel.

During this period, CCTV, which leading the tide of Chinese sports television, with the aid of the Athens Olympic Games, further improved the level of broadcasting and showed dominant status in Chinese sports TV broadcasting. Broadcasting of the three-dimensional concept continued in the 2004 Athens Olympics, 170 people were sent there and rent a400 square meters workshop. Main channel CCTV (China Central Television (CCTV) - 1, 2, 5) and two sets of digital pay channels, broadcast more than 1400 hours in total, which is double of the Sydney Olympics and a world-leading level (NBC, which bought out the broadcasting rights of the USA, broadcast 1500 hours with seven channels). In particular, in the broadcasting of this Olympic Games, CCTV took part in international public TV signal production of three projects including table tennis, badminton and modern pentathlon for the first time. This marks that the broadcasting level of CCTV in some sports has reached the international advanced level and got recognition in the track sports broadcasting industry. This is also a milestone in Chinese sports TV history. CCTV carried this Olympic coverage as one of the most important practice before the 2008 Beijing Olympic Games and gave a great deal of attention and full guarantee. Facts have proved that the large-scale transmission of Athens Olympic Games achieved very good training effect, it laid a solid foundation for CCTV's broadcasting of the Beijing Olympic Games.

Monopoly stage (from 2005 until now)

After the Athens Olympics in 2004, because of these reasons such as the policy, capital, resources, signal coverage and so on, insufficient natural salience of local TV sports channel exposed. While depending on various advantages including capital, talent, equipment, resources, policy inclination, CCTV is just like a duck to water in the international sports TV market featured of the broadcasting rights of "buy and sell". As early as before the Beijing Olympic Games, CCTV sports channel was in the absolute monopoly in sports broadcasting due to policy advantage and the benefits of "the first channel in China" status.

In the 2008 Beijing Olympic Games, CCTV took advantage of its host identity to further show the world its strength, and also promoted the broadcasting level of itself. After the Beijing Olympic Games, thanks to the economic strength, talent and brand strength accumulated during the Beijing Olympic Games, CCTV sports channel became the "big MAC" in China's sports television industry, and further established its monopoly position, thus making itself "alone big" with which no domestic peers could compete. CCTV announced its unshakable dominance to the domestic opponents.

\section{Conclusions}

At present, the domestic variety properties and forms of sports TV media, such as the local TV sports channel, CSPN (a joint sports TV broadcast platform composed of part of local stations), 
paid sports TV channel (Tiansheng media, etc.) and mobile TV, mobile TV can't compete with CCTV in a short period of time. Therefore, CCTV's monopoly of power in China has been formed in sports broadcasting market.

\section{References}

[1]Kuangyu Huang etc. Introduction to Radio and Television [M]. Guangzhou: Jinan University Press, 1999:75.

[2] Desheng Zhang. The General Theory of Sports Media [M]. Guangzhou: Guangdong People's Press, 2006:44.

[3] Kang Tan etc. TV Sports Edit and Production [M]. Chengdu: Sichuan Publishing Group, the Heavens And Earth Press, 2008:21.

[4] Guoqiang Chen. China's History and Current Situation of the Sports on TV. The Olympic Communication Research [M]. Beijing: the Communication University of ChinaPress.2009, 28.

[5] Radio and TV Sports Communication Research Committee. Proceedings of National Excellent TV Sports Journalist [M]. Beijing: China Broadcasting and Television Press, 2000:131. 